\title{
FLIPPED CLASSROOM MODEL USING ICT IN ENGINEERING EDUCATION
}

\author{
Sreelatha $\mathrm{R}^{1}$ \& Nalini $\mathrm{M} \mathrm{K}^{2}$
}

Abstract-Recent studies show that there should be some change in teaching learning methods. The integration of information and communication technology (ICT) provides more scope for the teachers and the students. There are some challenges which has to be faced while implementing the ICT. This paper aims at summarizing the use of ICT and the tools used in making an innovative teaching.

Keywords-ICT,Screen-O-Matic,Google-Forms,Moodle,OBE

\section{INTRODUCTION}

Recent technologies have emerged into the society those technologies have been involved in teaching learning process. ICT is one such technology. ICT stands for information and communication technology. ICT gives importance to the modern teaching learning process to be effective, the ICT has great impact on the society. ICT process of learning has been used in many countries it has a great benefit to the students.

Within a short span ICT became a core part of the education [1].Apart from the curriculum there is a need for some workshops and short trainings which introduce new techniques and activities which help us to promote for good teaching learning process. Higher education nowadays has drastic changes. There are different modes which have been adopted in teaching learning process. Different pedagogy, evaluation process have been involved.

These changes have made us to move towards outcome based education (OBE)[2]. The main factor which leads to significant role in implementing OBE is through the use of ICT in education for the best outcomes. The users of ICT has led to the tremendous potential changes and has a lot of improvement in sectors like education, healthcare and other government departments[3-4].

The use of ICT has focused more on the students rather than a teacher. Students have a lot of freedom to enhance the concept of the subjects at their own efforts with less dependence on regular classroom. ICT provides a lot of flexibility to a teacher to carry his or her own teaching process. It has become a supplement and a complement for the regular teaching process of a teacher which helps to improve the knowledge of the students [5].E-Learning technology is the backbone support for ICT. ELearning is purely based on the concept of information system called as LMS (Learning Management systems).It is a web based management system. It is a contribution of all the set of software's programs used to automate the needs such as tracking, reporting of online courses or programs used to automate the administration [6].CMS (Content Management System is also a part of eLearning. It is mainly designed to support education. It allows the faculties to create their own course website where documents can be uploaded in proper formats. It is a set of tools and a framework that allows the creation of online courses .The figure1 given below explains the classification of ICT. It is being classified into two type's ie Analog media where only voice can be heard. The other type is Digital media where voice is accompanied by a picture.

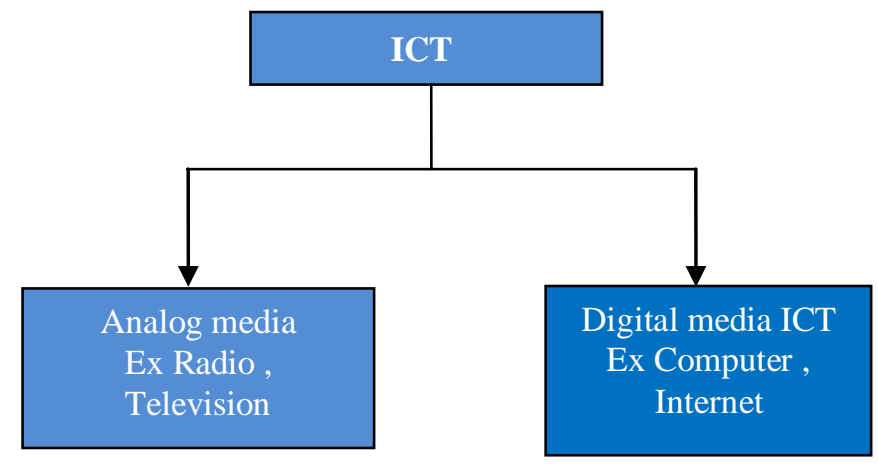

Fig1. Classification of ICT

\footnotetext{
${ }^{1}$ Department of Information Science, BMS College of Engineering, Bangalore, Karnataka, India

${ }^{2}$ Department of Information Science, BMS College of Engineering, Bangalore, Karnataka, India
} 
In this paper, the I section gives the introduction of the role of ICT in teaching learning Process. II section explains about the literature survey. III section is regarding the tools used for ICT. IV section explains the challenges of ICT. V section gives the conclusion

\section{LITERATURE SURVEY}

In this technological era, the new technology in education is essential. It proves to be very important. Hadi \& Zeinab[7] has done several studies and proves that use of new technology is very important. ICT in teaching helps and provides opportunities for teachers and students to work better to provide the information to the students. In this paper author has informed about some barriers which has led to discourage the use of ICT[7].Some of the barriers are insufficient technical supports, little access to internet, shortage of class time were some of the major disadvantage to use ICT in the classroom. Author has made a study to investigate the teachers intention of the barriers and the challenges faced by them to use ICT in the classroom. A few valid questionnaires were prepared for 30 high schools. Random sampling was used. The result showed that many faculities were interested in using ICT in the classroom. Due to some barriers they were not able to implement it.

Lakshmi Dhandabani \& Rajeev Sukumaran has discussed in their paper regarding the open source educational software, the Modular Object Oriented Developmental Learning Environment (MOODLE)[8]. It is one of the models used in ICT. The software seems to be more user friendly having numerous features. This paper mainly speaks about the use of digital technologies which is used in a blended learning model mooc for engineering education. The ICT has been used in all the fields mainly in the teaching-learning activities like content creation, administrative purpose, formative-summative assessments, student performance tracking, trainings etc.[8]. The author has discussed about the set of teaching-learning activities used for various subjects, infrastructure. Author has also discussed about the design of learning materials, lecturenotes has been updated in the tool. A random sample group of around 250 students were identified from different engineering discipline and e-survey was conducted.

Weiran Zhang etal[9] In his paper has discussed the concept of flipped classroom along with its features. Flipped classroom teaching model were elaborated. Flipped learning is a pedagogical approach in which direct instruction moves from one group to the individual learning. The author has compared traditional teaching with the flipped classroom teaching. Final results show that $72 \%$ improvement in the learning approach. The author has also discussed that the flip teaching is not replacing the teacher with videos. The role of the teacher becomes more important and active. It helps the students to watch lectures online.

\section{TOOLS FOR ICT}

As we are aware the importance of ICT in education, there is a need for ICT tools to make it successful. ICT tools are the devices and objects used for communication. They are the components used in technological systems. ICT tools can be classified into synchronous and asynronous. The details of the ICT tools are given below.

\subsection{Googleforms}

Teachers and students interaction can take place by using Google forms. Google forms are used for gathering the data .

It is a part of the goggle productivity and will be able to

create our own forms with the help of goggle account. Google form is a part of goggle docs. It is a simple way to collect information, conduct some surveys, quizzes can be conducted,

Questionnaires, feedback can be performed. It is a quick way for assessments. It can be saved in a spreadsheet and can be shared with a link or via email. The figure 2 given below shows the information which I have collected from the students for doing the groups for projects.

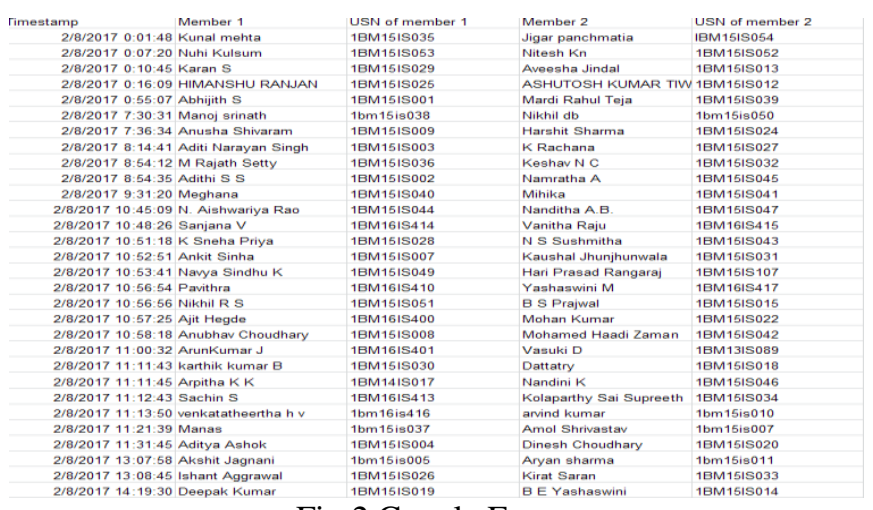

Fig 2 Google Forms 


\subsection{Screen-O-Matic}

There are many universities using video lectures for teaching and learning. Many universities have already started working on the procedures to get the video published. The video which is been recorded can be published in YouTube, iTunes, academic earth, Screencast-o-matic.com or video files can be stored. Screen-o-matic is one such tool used for recording. It is a free screen and a webcam recorder used to capture the video from your computer screen and share it to the public. It can be used for short tutorials, visual presentations and communicate while you demonstrate. This concept was implemented for the operating system. The video was recorded and published in YouTube by taking license. The figure $3 \& 4$ shows the recorded presentations and the link is also given https://www.youtube.com/watch?v=UctZk1paj0I\&feature=em-upload_owner

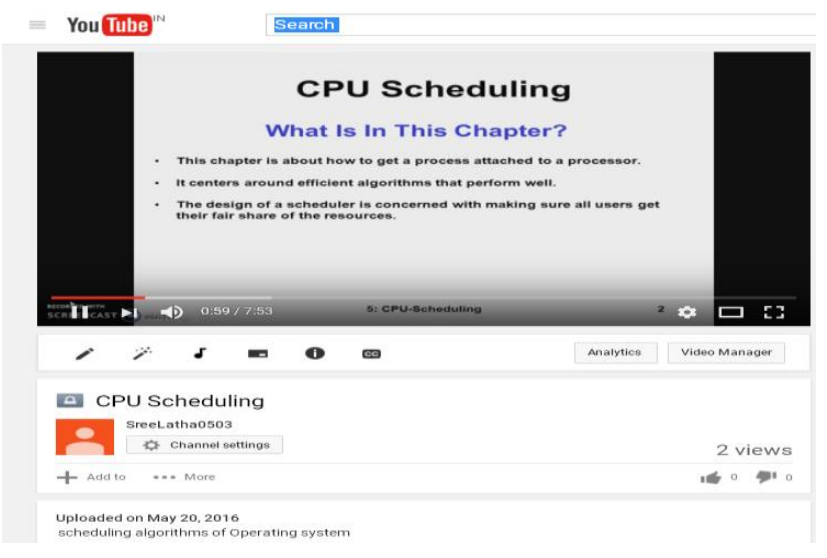

Fig: 3 Screen-o-matic used for recording

Fig-4: Screen-o-matic used for recording

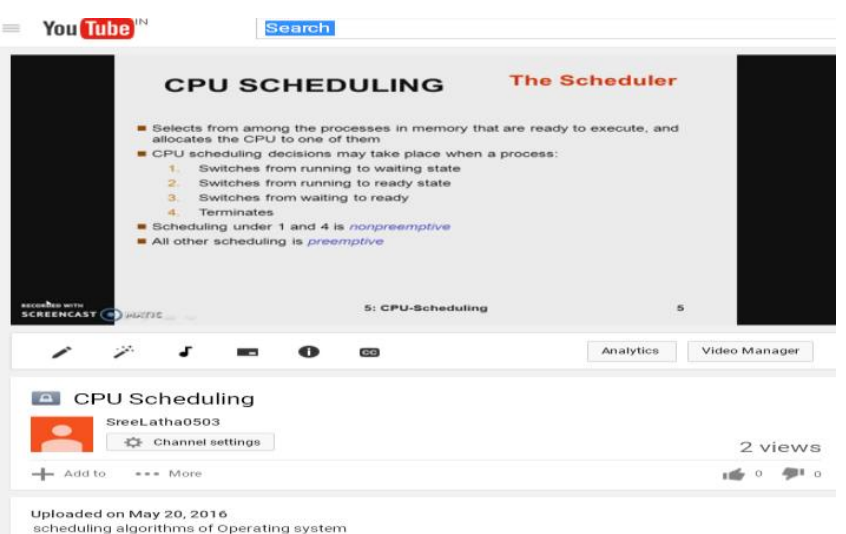

\subsection{Moodle}

Moodle is the factually supported online teaching and learning platform. It has designed to provide educators, learners and administrators with a single robust, secure and integrated system to create personalized learning surroundings. Moodle is used by many institutions and organizations It has some for the drag and drop features, simple interface and well documented resources along the usability improvements which make Moodle easy to learn and use .It is a freely open source software under the General Public License. (GNU). Moodle can be adopted, extend or modify for both commercial and noncommercial projects without paying any license fees. Moodle extends the most flexible tool-set to encourage both blended learning and $100 \%$ online courses. Figure 5 shows the website created in Moodle for operating system. The name of the website is given below http://sreebmsce.moodlecloud.com.

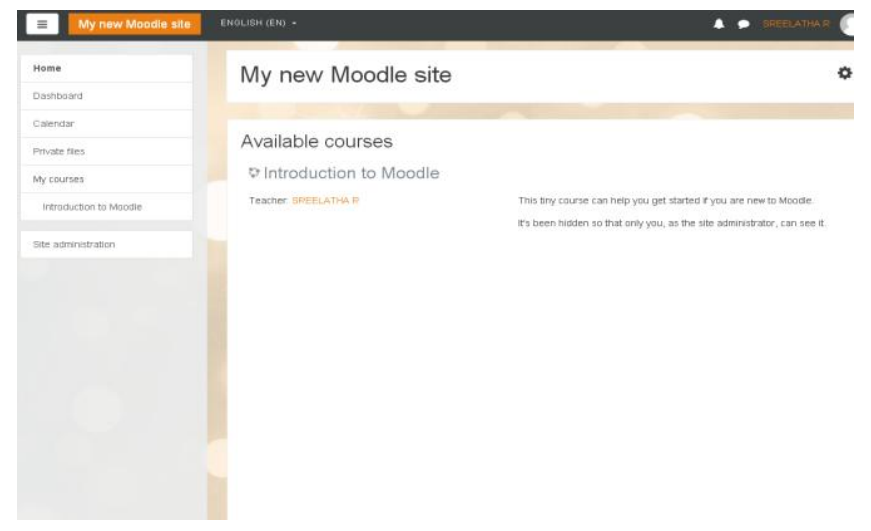

Fig 5. Moodle Website created

The Open education resource flipping the classroom with Moodle cloud quiz was done for operating system. Moodle Cloud quiz of operating system course helps the learner to have an exposure to Moodle cloud environment. It helps in active learning and dynamic thinking. It helps to develop the course knowledge. It explores information about concept mapping .Figure 6 Shows the website opened for operating system. Dates are given for the quiz to be taken by the students. 


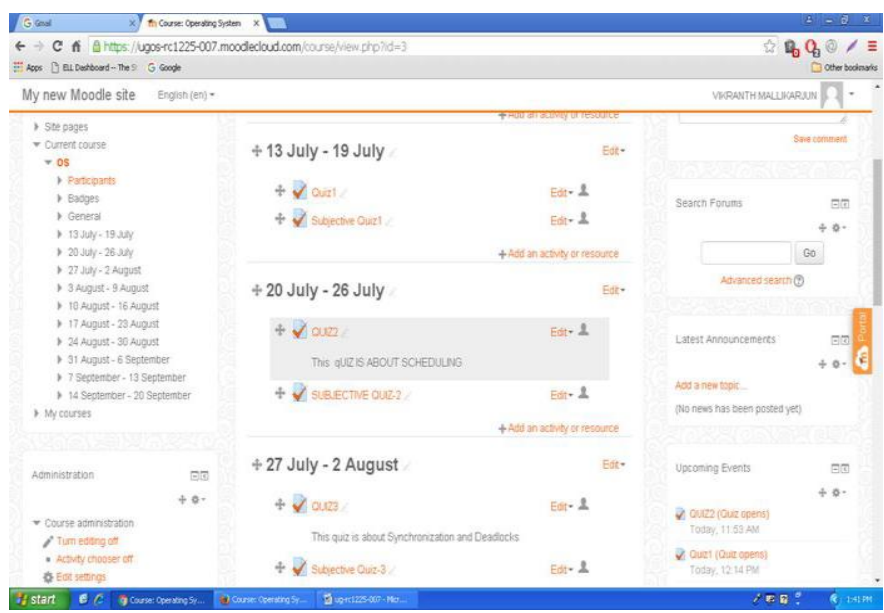

Fig 6. General appearance of Moodle cloud operating system course.

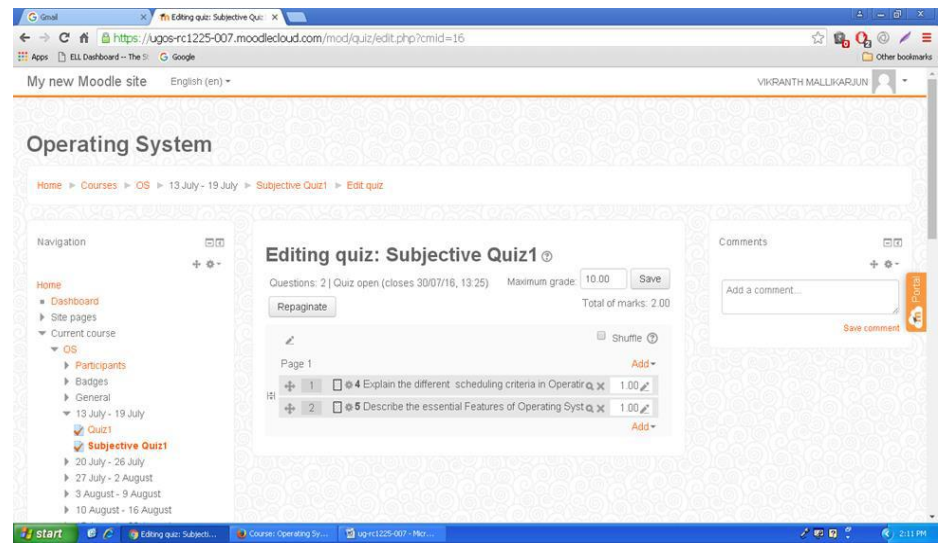

Fig. 7 Editing subjective quiz 2

The figure7 given above shows the snapshot of adding the questions in Moodle and editing it. Figure 8 shows the snapshot page of students attempting the quiz.

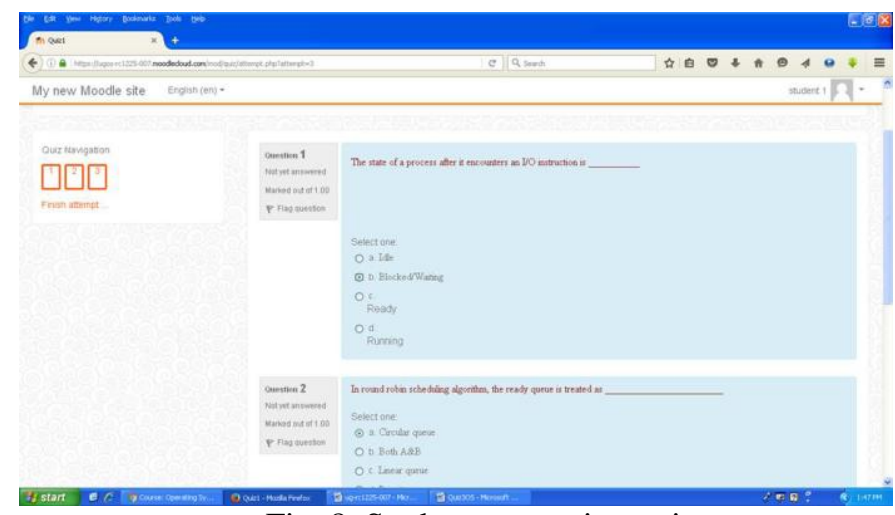

Fig. 8. Student attempting quiz

\section{CHALLENGES IN IMPLEMENTATION OF ICT}

Although ICT has the latency to improve education system, yet it is facing some problems in implementing these ICT in universities and colleges. Such problems are listed below.

\subsection{Lack of teachers trained}

Teachers have to be trained in using ICT tools such as moodle, flipped classroom.Lot of training has to be given to the teachers in order to implement this ICT in education. 


\subsection{Time Shortage}

ICT can be implemented if the strength of the students are very less if the strength is more than 60 in a class it is very tedious to implement. Since the whole syllabus has to be completed within three months.Lack of time is one such problem.

\section{3, Issues related to resource and internet}

The institutation should have a good Infra-structure, proper electricity supply, multimedia projectors, smart boards. A well versed classroom.In some instituions this might be a major problem.

\subsection{Insufficient funds}

Appropriate latest hardware and software availability should be there in the colleges. To purchase all the ICT tools sufficient funds should be avilabele. If there is any problem

\subsection{Less Technical Support}

The teacher will be responsible for the subject but when there is any lab held for the subject one teacher handling becomes difficult. Requirement is there for more technical lab instructor. They also to be well versed with the technologies.

\section{CONCLUSION}

Although teachers had some problems in implementing the ICT in the classroom. This study concluded that incorporating ICT in education help the students to understand the concepts very clearly. Many teachers also expressed their willingness to learn new teaching techniques and employed more innovative and creative approaches. We can precisely predict that there will be many benefits for the teacher as well as students when we use ICT. The uses of ICT will enhance the learning experience. It helps for students to think and communicate creatively.

\section{ACKNOWLEDGMENT}

We thank BMS College of Engineering for providing the support for implementing this paper. In particular our beloved Principal, Vice-Principal, Dean Academic, HOD of ISE, TEQIP for supporting constantly.

\section{REFERENCES}

[1] Dr. Meenakshi, "Importance of ICT in Education", Jammu Vol. 1,Issue-4, pp. 2320-7388,P-ISSN, April 1955. (references)

[2] P. Srinivasa Pai, Niranjan N. Chiplinkar, B. R. Shrinivasa Rao, K. SubrahmanyaBhat Volume 30, Issue 1, July 2016 -“ Effective Use of Information and Communication Technology in Enhancing Teaching-Learning Outcomes:Some Thoughts"

[3] Sujatha,Rajshri Jobanputra and R V Joshi(2011).doi 10.1109/T4E.2011.

[4] Mansotra V,Vinod Sharma \& Sambyal G S (2009) doi:10.1109/ICCSIT.2009.5234382

[5] Mario Edelmiro Antunez, MariaKolb Koslosky \& Veronica Marina Longobardi (2014) doi: 10.1109/IMCTL. 2014.7011100 .

[6] “CMS,LMS \& LCMS for elearning” IJCSI International Journal of Computer Science Issues, Vol.8, Issue 2 March 2011. ISSN(online): $1694-0814$.

[7] Hadi Salehi \& Zeinab Salehi, "Challenges for Using ICT in Education : Teachers"-Insights, International Journal of e_Education,e-Business,eManagement and e-Learning, Vol.2, No 1, February 2012.

[8] Lakshmi Dhandabani \& Rajeev Sukumaran, "Use of ICT in Engineering Education : a Survey Report", IEEE, 2014.

[9] Weiran Zhang, Rongxia Wang \& Jinjun Chen, “Flipped Classroom Model Based Instruction of College English in ICT Environment”, ICADCE 2015 